\title{
Formation of the sustainable development mechanism at enterprises of mining industry as a condition of overcoming crisis
}

\author{
V.V. Zhuravlyov ${ }^{1, *}$ \\ ${ }^{1}$ South Ural State University, Chelyabinsk, Russia
}

\begin{abstract}
The present article addresses problems of sustainability at enterprises of gold mining industry of the Russian Federation in the period of recession. The author analyses environmental factors and tendencies of global economic development that have an impact on Russian business. On the basis of studying academic papers of foreign and Russian researchers the author offers a simulated model for operations of the gold mining enterprise, which is considered as a stochastic non-linear dynamic system. The model allows to identify diapasons of stability, to make a quantitative evaluation of the economic status of the enterprise in conditions of crisis phenomena. The author offers a mechanism of sustainable development for enterprises of mining industry that involves applying a complex of methods and techniques aimed to enable the company to perform its goal function.
\end{abstract}

\section{Introduction}

The world financial crisis, marked aggravation of political situation all over the planet, and instability of economic ties resulted in the situation when many states are turning their close attention to formation of gold-exchange reserves and increasing the gold reserve stock. Gold mining is one of key branches that guarantee economic security of the country. In recent years we have witnessed a stable growth of the amount of gold mined in the Russian Federation; number of enterprises engaged in this activity is increasing, purchases of precious metals are on the rise, as well as the demand of the Russian state addressed to representatives of the "gold business". Strategic role of the gold-mining industry certainly contributed to its progressive advance. Nevertheless, recessionary phenomena in the world economy together with sanctions imposed by the USA and European Union, a de facto stagnation of the Russian economics caused great difficulties for enterprises of the mining industry. Stability of the industry depends on a number of both controlled and uncontrolled factors of external and internal environment.

Gold-mining has certain number of peculiarities, for example, it is not an infrequent case when prognostic recovery factors prove to be wrong, many of developed deposits are found being unprofitable. The principal deposits developed as far back as in the Soviet times are located in hard-to-reach places in Eastern Siberia and Yakutia. Gold deposits are explored and mined in difficult climatic conditions. Quite often there exist neither reasonable infrastructure nor roads, so it is possible to deliver equipment, materials, instruments, fuel only during a certain time of the year. Other unfavourable external forces include purchasing prices for an ounce of gold, rouble exchange fluctuations, inflationary processes, etc. [1].

The internal environment of the gold-mining enterprise is specified by the state of maintenance, technologies, equipment, qualifications of personnel, a possibility to introduce novelties, the volume of own financial resources [2]. The equipment status depends on climate and the level of excellence of workers, and in its turn it influences the correlation between the operating time and the time spent on repair works; it also determines expenditures connected with equipment handling. Small mining enterprises are facing problems connected with their intention to buy and operate very expensive, but high-quality, user-friendly and productive foreign pieces of equipment. At the same time, larger companies that have been able to renovate their production facilities in time, are now anxious about such matters as, above all, further training for their staff, labour motivation, and quality of works.

Hence, controlled and uncontrolled factors of external and internal environment, which determine the actual situation in gold-mining, call for analysis, intensive study and timely response by means of formation and perfection of a mechanism of sustainable development at enterprises of mining industry in the context of economic recession.

\section{Theoretical framework and literature review}

Theoretic aspects of development, formation and perfection of the mechanism of sustainable development at industrial enterprises are considered in works of such foreign researchers as R. Daft, J.L.

* Corresponding author: eltcha@mail.ru 
Laft, M. Robson, Joseph Alois Schumpeter, J. Heywood and others.

Works of Russian scholars devoted to methodological issues of stability of economic systems also present a great interest, namely works of D.R. Ageeva, A.V. Bezgodov, O.V. Bratkov, L.V. Volkova, D.S. Kondaurova, A.G. Koryakov, O.V. Mikhalev, V.M. Tumin.

Theoretical and practical problems of economic stability at mining and gold-mining enterprises are studied in research papers of R.A. Arend, R.S. Moiseev, T.V. Petrov, A.N. Strekhin, V.M. Shek.

Theoretic research in the field of businesses evaluation is presented in papers of such foreign and Russian scholars as G.M. Desmond, G.S. Harrison, R. Link, R. Reily, C. Wally, V.V. Balakirev, V.V. Grigoriev, A.G. Gryaznova, E.D. Chikina, V.A. Shcherbakov and others.

Problems of modelling parameters and stability conditions for enterprise are presented in scientific papers by T.S. Bulyshev, I.V. Dodonov, A.I. Kibitkin, V.D. Kovalyov, K.A. Miloradov, L.B. Senetskaya.

Reviewing academic papers on the given issue, as well as studying practices of economic activities at industrial enterprises in modern conditions, highlighted practical obstacles in implementing the sustainable development strategy. Practical problems are also evidenced by imperfection of management procedures applied by enterprises. One of such imperfections is that there is no effective model designed to assess and forecast the value of the enterprise, which would take into account an inherent uncertainty of external factors.

The object of the research is sustainability of a Russian industrial gold-mining enterprise in volatile external environment, when exposed to recessionary influences.

The goal of the article is designing and formation of the sustainable development mechanism of an industrial enterprise and introducing this mechanism into practical activities of mining enterprises of the Russian Federation.

\section{Materials and methods}

\section{A. Methods Description}

An industrial enterprise is a dynamic open goal-based nonlinear system [3]. The system dynamics can be presented as a change of properties, parameters, which brings about absolutely new states of the system and thus provides for stability while launching certain qualitative characteristics [4].

Sustainable development is ensured by such a response to external impacts that allows to minimize their negative influence through anticipation and making expert managerial solutions [5,6]. Effectiveness of such solutions accounts for the precision of the enterprise management mechanism, which includes assessment of the economic stability of the enterprise and clearly defined algorithms of crisis management [7]. Examination of works on the theory of systems, unstable state of industrial objects, together with considering specific features of mining enterprises, demonstrated that in gold-mining industry we should view enterprises as stochastic non-linear dynamic systems.

Having reviewed research papers by V.V. Kovalchuk, L.B. Senetskaya, A.V. Shmidt, T.A. Khudyakova, the author offers the simulation model aimed to model business processes based on analysis of financial, economic, technical and other parameters in the state of instability $[8,9]$. The said model is to serve as an instrument of quantity assessment with regard to stability of gold-mining enterprises.

For managers it is essential to make an adequate consequence of decisions based on assessment of the state of the enterprise, which would facilitate overcoming recessionary phenomena.

An adequate assessment of the current situation and timely managerial decisions enable the enterprise to implement the strategy of sustainable development provided there has been formed a mechanism designed to regulate unstable economic systems [10, 11 .

The sustainable development mechanism for enterprises of the gold-mining industry should be defined as a system of consecutive managerial impacts of the managerial subsystem made on the microeconomic system; herewith, these impacts are aimed to ensure that the enterprise performs its functions and has a longer life cycle in the framework of implementing a proper strategy.

The mechanism of sustainable development of gold-mining enterprises includes fundamental action blocks that correspond to the managerial function, a system of monitoring environment, parameters of making decisions, and obtaining a feedback. Altogether it provides for the possibility to anticipate external challenges and to respond to them in a timely and precise manner [12, 13].

Algorythm of search for methods aimed to enhance efficiency of the management system

To launch the mechanism of sustainable development of gold-mining enterprises it is necessary to introduce the simulation and block models of business development, which requires application of a step-by-step approach with the following stages:

The forecasting stage, which implies examination of trends of social and economic development, consideration of statistical data aimed to identify possible scenarios of the enterprise business activity.

The analysis stage, which involves an all-around analysis of different aspects of the enterprise operation. The key criterion here is completeness of information, which allows to estimate how balanced and proportionate the enterprise is, and also to consider its potential for sustainable development.

Organisation and administration stage, which consists in setting up the mechanism of sustainable development of the industrial enterprise, and 
introducing the model of making assessments and taking decisions.

Procedures and pragmatics stage, which involves designing necessary managerial solutions, recommendations, principles, management methods.

Control and adjustment stage allows to compare results of development management with data from prior periods, and to detect deviations.

\section{B. Graphic model}

An existing experience of modelling activities of industrial enterprises demonstrates that it is essential to conduct an intensive study and thoroughly consider all external and internal factors, without which realistic evaluation of the state of the enterprise is totally impossible [14].

The simulation model of the enterprise activity involves estimating the probability of loss occurrence at the end of the simulated period with provision for changes in the environment parameters, identification of diapasons where the state of the enterprise is not stable, and their quantitative assessment necessary to form the sustainable development mechanism (Fig. 1).

Government procurement

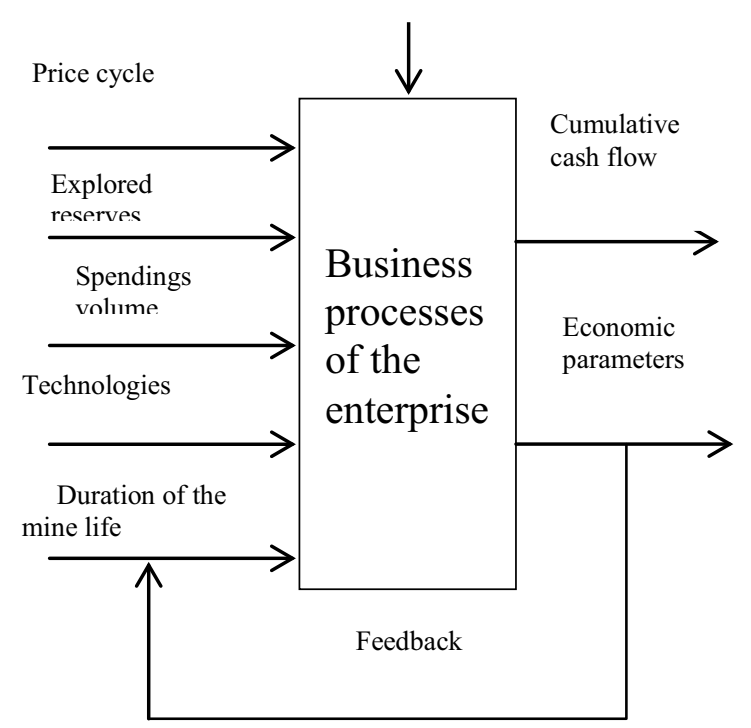

Fig. 1. The simulation model of value analysis for a goldmining enterprise.

This simulation model serves as the basis for conducting assessment of statistical probability concerning occurrence of recessionary phenomena and prospective losses occurrence at the end of the fixed period of activity of the enterprise, which would take into account changes in environmental parameters characteristic of the given industry sector. The model deals with three diapasons that correspond to possible stability states of the enterprise, where the first is the diapason of return, and the third is the diapason of necessary bankruptcy, which can occur if managerial actions during the transition diapason were unsatisfactory.
Business practice suggests that the gold-mining enterprises most exposed to instability are enterprises that mine deposits with expected reserves of less than 50 tons, with the average duration of the deposit mining (life of mine) up to 7 years during phases in the price cycle when the price for gold is low [15].

Each of the mentioned stability diapasons is specified with characteristic values for dynamic and static parameters. Dynamic parameters consider the daily average rate of changing cumulative cash flows. This rate has a tendency to decrease when the enterprise moves to the transition diapason, and then to the diapason of necessary bankruptcy, when the monetary funds of the enterprise decrease drastically and the enterprise generate losses.

In order to enable a timely response to instable operation patterns at the enterprise, it is necessary to activate the mechanism aimed to control the state of such economic agents that got in a hazard-prone area, in a crisis situation. Core elements of the given mechanism are schematically presented below (Fig. 2).

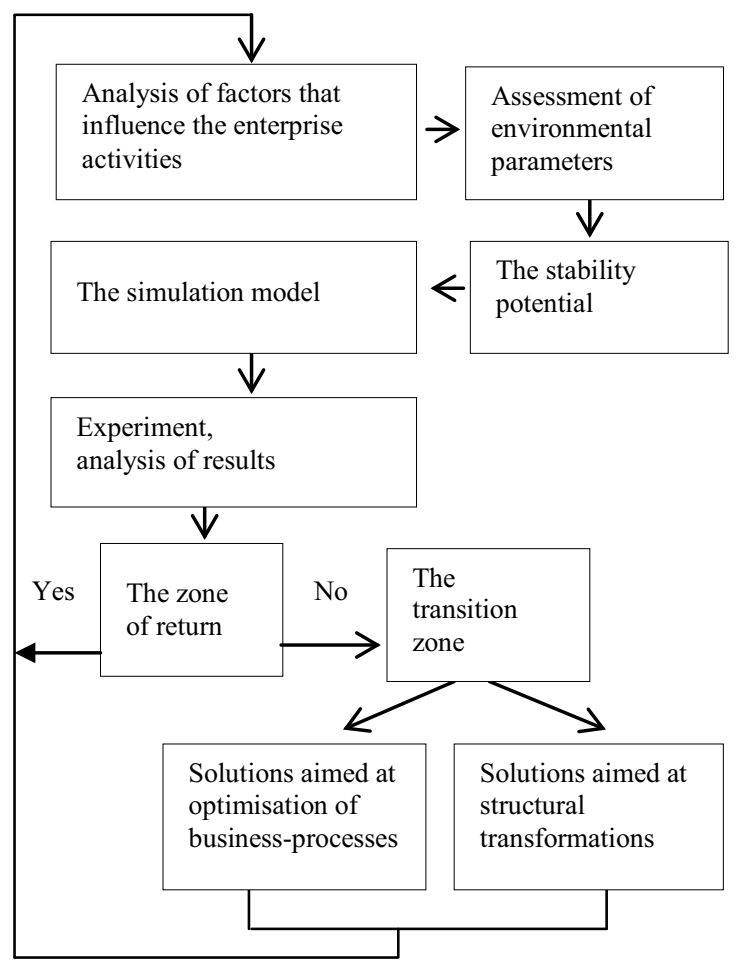

Fig. 2. The sustainable development mechanism for a goldmining enterprise in a crisis situation.

The present model takes into account the fact that operation of the mining enterprise is subjected to numerous external and internal environment factors. It also provides for monitoring the enterprise stability parameters, developing and applying certain instruments designed to activate the stability potential and perform an integrated management at the goldmining enterprise [10].

The given model allows to detect environmental challenges and to undertake adequate steps to overcome crisis situations by means of developing appropriate managerial solutions. For example, 
solutions aimed to improve business processes at gold-mining enterprises imply the following actions: using advanced resource saving technologies; optimisation of processes of developing gold reserves with due account for climatic conditions of Yakutia, Kamchatka, Far North; providing advanced vocational training and career enhancement for staff members; launching new forms and methods in the field of employee engagement. The described complex of measures, as evidenced by practices of the enterprises under analysis, i.e. AO "Serebro Magadana" (Silver of Magadan), OAO "Polymetal", allows managers to increase labour productivity and volumes of extracting precious metals by $5-7 \%$ [16].

It is essential to apply a rational approach when replacing import technologies and equipment with domestic ones, which are cheaper and more reliable in conditions of permafrost, since they allow to continue the process of extraction and beneficiation of ores in conditions of great drops in temperatures in wintertime $[17,18]$.

Managerial solutions connected with structural transformations imply merging, setting up partnerships between enterprises. This is due to the fact that maximum efficiency is achieved by enterprises, which mine deposits with expected reserves from 100 to 300 tons, with the average duration of the deposit mining (life of mine) $15-20$ years.

Implementation of managerial solutions made in the framework of the sustainable development mechanism results in increased net cash flows, decreased losses risks, a consolidated competitive position of the enterprise [19]. Applying the sustainable development mechanism produces a synergetic effect, accounted for operations improvement, reduction of expenses and increase of income of the mining enterprise [20].

\section{Economic and mathematical model}

The simulation model of business operations in the gold-mining industry sector allows to model activities of economic agents in the situation of uncertainty and expect improvements only under the condition that that there was performed a proper analysis of necessary parameters that depend on the impact intensiveness on the part of internal and external environment factors.

In order to ensure maximum precision of quantitative estimation of parameters of the diapasons that correspond to stability states of the gold-mining enterprise, it is recommended to use the estimate of probability of occurrence of the losses risk P. In this case the time interval under analysis should be divided into diapasons. The offered model is based on assessing the probability of occurrence of a prospective loss at the end of the period subject to modelling.

$$
P=A(d, r, g, s)+B(d, r, g, s) K+C(d, r, g, s) K
$$

where $P$.is probability; $\mathrm{ABC}$ - coefficients whose values depend on $\mathrm{d}, \mathrm{r}, \mathrm{g}, \mathrm{s} ; \mathrm{d}$ - duration of the deposit mining (life of mine); r,g,s - change in price for gold, rent of the minefield (a lot with the deposit), exploration (search) of the actual reserves; $K-$ a number of units $X$ in the amount of financial assets of the enterprise for the beginning of the period; $X$ characteristic value, which stands for the means necessary to exploit the deposit.

\section{Conclusions}

In conclusion we should note that analysis of theoretic sources and conceptual approaches used in studies devoted to how economic systems behave in conditions of crisis, together with summarising practical experience of assessing stability of industrial enterprises suggest that enterprises in the sector of gold-mining should be viewed as stochastic dynamic nonlinear systems.

In order to estimate probability of occurrence of a prospective loss we offer to employ a method of the simulation modelling of activities at the gold-mining enterprise, which involves changing parameters of internal and external environment. The simulation model allows to distinguish three stability diapasons, specify their borders, perform a quantitative estimation of the position of the enterprise in the context of recessionary phenomena, estimate a probability of loss occurrence for the economic agent for the end of the period, which is subject to modelling.

We offer the sustainable development mechanism for enterprises of gold industry that involves analysis of environmental factors, assessment of the sustainable development index (SDI), monitoring external and internal environment, management methods and tools that allow the enterprise to respond crisis phenomena in a timely and successful manner, and to adjust the development strategy.

The work was supported by Act 211 Government of the Russian Federation, contract № 02.A03.21.0011.

\section{References}

1. R. Arend, Questions of Economics, 24-36 (2006)

2. A.S. Gorevsky, Crisis Management (INFRA-M, Moscow, 2011)

3. T.A. Khudyakova, A.V. Shmidt, Proc. of The 26th International Business Information Management Association Conference, 1626-1634 (2015)

4. A.G. Koryakov, Questions of Economy and Law, 4, 42-49 (2012)

5. T.G. Kasiyanenko, Business Valuation: textbook for bachelor students (The Publishing House URIGHT, Moscow, 2014) 
6. A.V. Shmidt, T.A. Khudyakova, Proc. of The 27th International Business Information Management Association Conference (2016)

7. D.R. Kondaurova, Proc. Enterprise, Economics, Management, Finance, 130-132 (2012)

8. I.A. Baev, V.I. Shiryaev, E.V. Shiryaev, Dynamic theory of the firm, Monograph (SUSU Publishers, Chelyabinsk, 2001)

9. V.V. Kovalchuk, L.B. Senetskaya, Bulletin of Moscow State Technical University, 13, 1, 136$140(2010)$

10. T.A. Khudyakova, Proc. of the International Congress on Interdisciplinary Behavior and Social Science, 292-294 (2015)

11. O.V. Mikhalev, Economic Stability of Household Systems: Methodology and Practice of Research and Application Analysis (Publishing House of St. Petersburg Academy of Management and Economy, St. Petersburg, 2010)

12. T.A. Khudyakova, A.V. Shmidt, Proc. of The 26th International Business Information Management Association Conference, 1612-1616 (2015)
13. T.A. Khudyakova, Proc. of the International Congress on Interdisciplinary Behavior and Social Science, 295-297 (2015)

14. N.V. Rodionova, Crisis Management (Publishing House UNITY, Moscow, 2012)

15. T.A. Khudyakova, Actual problems of economics, 12, 444-450 (2015)

16. M.V. Lysenko, Fundamental Research, 4(1), 56$61(2013)$

17. T.A. Khudyakova, A.V. Shmidt, Proc. of The 26th International Business Information Management Association Conference, 1617-1625 (2015)

18. O.A. Nikolayevskaya, Management of development of the industrial enterprises on the basis of cost approach, Monograph (Creative economy, Moscow, 2013)

19. Z.P. Rumyantseva, Organisation Management: study guide (INFRA-M, Moscow, 2010)

20. R.S. Golov, Innovation and Synergetic Development of Industrial Enterprises (Theory and Methodology) (Dashkov and Co, Moscow, 2012)

21. T.A. Khudyakova, A.V. Shmidt, Mediterranean Journal of Social Sciences, 6, 4, 274-279 (2015) 